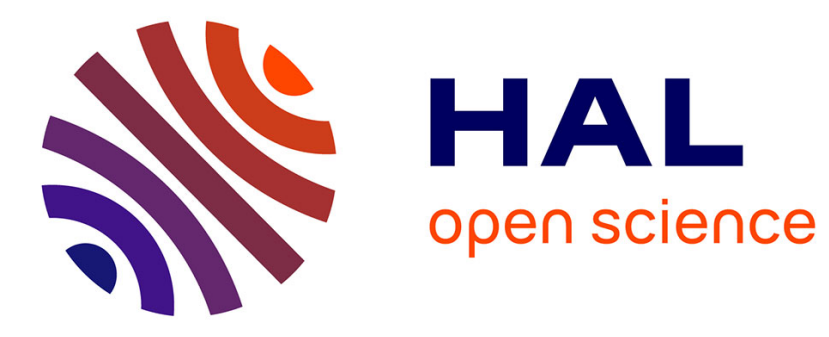

\title{
The intransitive basis of Movima clause structure Katharina Haude
}

\section{To cite this version:}

Katharina Haude. The intransitive basis of Movima clause structure. Ergativity in Amazonia, John Benjamins Publishing Company, pp.285-315, 2010. halshs-00670553

\section{HAL Id: halshs-00670553 https://shs.hal.science/halshs-00670553}

Submitted on 15 Feb 2012

HAL is a multi-disciplinary open access archive for the deposit and dissemination of scientific research documents, whether they are published or not. The documents may come from teaching and research institutions in France or abroad, or from public or private research centers.
L'archive ouverte pluridisciplinaire HAL, est destinée au dépôt et à la diffusion de documents scientifiques de niveau recherche, publiés ou non, émanant des établissements d'enseignement et de recherche français ou étrangers, des laboratoires publics ou privés. 


\title{
The intransitive basis of Movima clause structure
}

\author{
Katharina Haude \\ khaude@uni-koeln.de
}

\begin{abstract}
In Movima (unclassified, lowland Bolivia), the arguments of a transitive clause are basically encoded according to the position of their referents in a salience hierarchy, which includes deictic, semantic, and pragmatic levels. The participant roles of the arguments (actor or undergoer) are indicated by direct and inverse marking on the predicate. The argument whose referent is lower in the hierarchy is encoded in the same way as the single argument of intransitive clauses, and it also has a privileged syntactic status. This results in an unusual split-ergative alignment pattern: the direct construction, which is pragmatically unmarked, patterns ergatively, and the inverse construction patterns accusatively. I propose that the system can be accounted for by the syntactic similarity of nouns and verbs and the identical encoding of the possessor and the salient argument of a transitive clause. Both transitive and intransitive clauses may, therefore, have arisen from an intransitive equational construction with either a monovalent/nonpossessed or a bivalent/possessed predicate nominal.
\end{abstract}

Key terms: transitivity, inverse, hierarchies, ergativity, alignment split, equational clauses

\section{Introduction ${ }^{1}$}

Movima is an unclassified, endangered language still spoken by perhaps a thousand adults in and around Santa Ana del Yacuma in the Beni department of lowland Bolivia. The language was first investigated by the SIL linguists Robert and Judith Judy in the early 1960s. The present study is based on a corpus of elicitation and about 12 hours of text data from approximately 15 speakers during a total of 15 months collected by myself between 2001 and $2007 .^{2}$

The phoneme inventory of Movima contains 19 consonants (represented orthographically with phonetic specification when not self-explanatory): $p, t, k$ (realized as [p $\left.\widetilde{2}^{\mathrm{m}}\right],\left[\mathrm{t} \mathrm{?}^{\mathrm{m}}\right]$, and [?], respectively, in coda position), ' [?], $k w, b[6], d[\mathrm{~d}], c h\left[\mathrm{t} \int\right], v[\beta], s, j[\mathrm{~h}], t, m, n, l, r[\mathrm{r}], w, y$ [j], and $y^{\prime}\left[\mathrm{j}^{\mathrm{P}}\right]$. The five vowel phonemes are $i, e, a, o$, and $u$. Syllable structure is $(\mathrm{C}) \mathrm{V}(\mathrm{C})$ or (C) V(:). Stress generally falls on the penultimate syllable of the word, except when the word ends in a glottal(ized) consonant, which causes stress on the last syllable. A penultimate open syllable is usually lengthened, the major exception involving words that end in the glottal stop. Lexical roots must minimally consist of a heavy syllable, i.e. (C) $\mathrm{VC}$ or (C) V:. Morphologically, Movima is agglutinating (one morpheme = one meaning), but many content words are synchronically monomorphemic. Most morphemes are suffixes, but there is one prefix (the oblique marker $n$-) as well as infixes and several reduplicating processes.

\footnotetext{
1 This paper was prepared within the Movima documentation project financed by the Volkswagenstiftung (DoBeS programme). The ideas discussed here (or earlier stages thereof) were presented at various meetings and conferences since 2005, and I wish to thank all the colleagues who commented on them. I am especially grateful to Werner Drossard and Nikolaus Himmelmann for inspiring discussions, and to Hans-Jürgen Sasse, the editors of the present volume, and an anonymous reviewer for comments on earlier versions of this paper. My deepest gratitude is with the speakers of Movima who shared their knowledge with me, in particular, Esaltación Amblo Ovales for last-minute elicitation sessions. The usual disclaimers apply.

${ }^{2}$ The data presented here were contributed by Esaltación Amblo Ovales, Jovina Amblo Ovales, Masimina Cayalo Almaquio, Eligardo Chirimani Malue, Etelvina Gualusna Amblo, Julia Malale Humasa, Herlan Rojas Rossel, and Ela Rossel Chori. The texts are currently being archived in the DobeS archive at the Max-PlanckInstitute for Psycholinguistics, Nijmegen (http://corpus1.mpi.nl/ds/imdi_browser/).
} 
Compounding and noun incorporation are frequent. Tense, mood, and aspect are not expressed by verbal morphemes, but by particles. Referential elements (articles, personal pronouns, demonstratives) indicate natural gender, number, presence, absence, position, and ongoing vs. ceased existence of the referent. ${ }^{3}$

Movima clause structure, the topic of the present paper, is characterized by largely fixed constituent order (predicate initial). Case marking is restricted to the distinction between structural (unmarked) and oblique (morphologically marked) case. The organization of transitive clauses is governed by referential properties of the arguments according to a salience hierarchy: the argument that denotes the nonsalient participant in a two-participant event has the same coding properties as the argument of an intransitive clause; this argument also has the syntactically privileged status. Direct and inverse marking on the predicate indicate the participant roles of the arguments in a transitive clause, direct indicating that the salient participant is the actor and the nonsalient participant the undergoer, inverse indicating the opposite constellation. The direct construction patterns ergatively and the inverse construction patterns accusatively. A valence-decreasing voice operation enables the argument encoding the salient participant in a two-participant event to function as the privileged syntactic argument.

In the following two sections (2-3), argument encoding in intransitive and transitive clauses is described in more detail. Section 4 then presents the ergative-accusative alignment split pattern and demonstrates that the ergative construction is pragmatically unmarked. Section 5 presents a possible explanation of the facts: the syntactically privileged status of the less salient argument may have arisen from the identical encoding of the salient participant and a nominal possessor in connection with the nearly identical syntactic status of nouns and verbs. In this way, at least from a hypothetical historical perspective, all clauses can be interpreted as intransitive, equational clauses. The direct/inverse opposition may be a grammatical reflection of the the cognitive parallel between a prototypical transitive event and a prototypical possessive relationship.

I will concentrate as far as possible on the encoding of third persons in affirmative main clauses. Most of the claims put forward here also hold for first and second person, whose encoding is, however, more difficult to describe (cf. Haude 2006: 268ff.; Haude to appear a). Subordinate and negated clauses involve nominalization and therefore have a slightly different person encoding pattern (cf. Haude 2006: 305ff.).

\section{The structure of simple clauses}

Canonical clauses are predicate-initial. The predicate consists of a content word, typically a verb. The arguments appear as pronouns or as determiner phrases (DPs), the latter consisting of a content word (typically a noun) preceded by a determiner, typically an article. To facilitate the understanding of the examples below, the articles and the third-person pronouns are listed in Tables 1 and 2, respectively. Note that the article does not mark definiteness, but is used for definite as well as for indefinite reference.

\footnotetext{
${ }^{3}$ For detailed information on the Movima phonology and grammar, see Haude (2006).
} 
Table 1. Articles ${ }^{4}$

\begin{tabular}{l|l|l|l}
\hline & presential/generic & absential & past \\
\hline masculine & us & kus & us \\
feminine & i'nes & kinos & isnos \\
neuter & as & kos & os \\
plural & is & kis & is \\
\hline
\end{tabular}

Table 2. Third-person pronouns

\begin{tabular}{|c|c|c|c|c|}
\hline & \multicolumn{2}{|c|}{ presential } & \multicolumn{2}{|c|}{ absential } \\
\hline & free & enclitic $^{5}$ & free & enclitic \\
\hline $\begin{array}{l}\text { masculine } \\
\text { feminine } \\
\text { neuter } \\
\text { plural }\end{array}$ & $\begin{array}{l}\text { u'ko } \\
\text { i'ne } \\
\text { a'ko } \\
\text { i'ko }\end{array}$ & $\begin{array}{l}u^{\prime} \\
\text { (i)'ne } \\
a^{\prime} \\
i^{\prime}\end{array}$ & $\begin{array}{l}\text { usko } \\
\text { isne } \\
\text { asko } \\
\text { isko }\end{array}$ & $\begin{array}{l}\text { us } \\
\text { (i)sne } \\
\text { as } \\
\text { is }\end{array}$ \\
\hline
\end{tabular}

\subsection{Argument encoding in intransitive clauses}

Intransitive clauses may contain one DP or pronoun that is not marked as oblique. All noncore DPs and pronouns are overtly marked as oblique by the prefix $n$-. In (1), the core argument is represented by a DP: ${ }^{6}$

$$
\begin{array}{llll}
\text { joy-chet } & \text { us so:te } & n \text {-os } & \text { sot-lo:los } \\
\text { go-R/R } & \text { ART.M other_person OBL-ART.N.PST } & \text { other-village } \\
\text { 'The other (man) went to another village.' } & \text { [HRR_300703 191] }
\end{array}
$$

When the argument of an intransitive clause is realized as a pronominal enclitic, it is attached to the predicate through "external clitization" (to be explained in 2.2), which is represented by a double dash ( -- ). It can also be encoded by a free pronoun before the predicate, as in (3) (see 3.1 below for this construction).

$$
\begin{aligned}
& \text { kuyna:nak--i’ne } \\
& \text { play--3F } \\
& \text { 'She plays.' }
\end{aligned}
$$

[EAO_Basket 010]

\footnotetext{
4 "Presential" and "absential" indicate presence at or absence from the speech situation; "past" indicates that the referent has ceased to exist.

${ }^{5}$ The glottal stop of $u^{\prime}, a^{\prime}$, and $i^{\prime}$ is dropped when the pronoun is cliticized to a vowel.

${ }^{6}$ Core arguments are underlined in the examples. Elicited examples, which usually stem from more than one speaker, are marked as [e]; for text examples, the speaker acronym, the title of the text, and the record number in my Toolbox database are indicated. Spontaneous utterances that occurred during eliciation are marked as [spont.]. Examples that lack a source indication are frequently occurring expressions. When tense is not overtly encoded, elicited examples are translated with the English present tense and text examples according to the context. Since definiteness is not a morphological category in Movima (see Haude 2006: 142), the choice of the definite or indefinite English article is generally based on my intuition and should not be considered relevant.
} 


\section{i’ne kuyna:nak}

PRO.F play

'She plays.'

When the argument is known from the context, it can be omitted, so that an intransitive clause can consist of the predicate alone:

$$
\begin{array}{llll}
j i: y i & \text { che ji:yi che ji:yi } \\
\text { cry and cry and cry }
\end{array}
$$

'(She) cried and cried and cried.'

[EAO_Desvelada 006]

\subsection{Argument encoding in transitive clauses}

Transitive clauses are identified by the fact that they may take two core arguments, i.e. two DPs or pronouns that are not marked as oblique. In a canonical transitive clause, both arguments follow the predicate, as in (5).

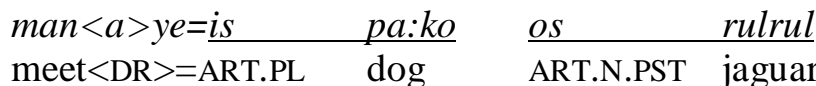

$$
\begin{aligned}
& \text { 'The dogs found a jaguar.' }
\end{aligned}
$$

[EAO_Tigre y perro 003]

Apart from linear order, several other factors distinguish the two arguments of a transitive clause. The argument that comes first after the predicate is obligatorily expressed and phonologically closely attached to the predicate through "internal cliticization" (see below). The argument in second position, in contrast, has the same properties as the argument of an intransitive clause: its overt realization is not grammatically obligatory; it has a freer position in the clause; when represented by a pronominal enclitic, it is attached through "external cliticization" (see below).

As will become clear in the following sections (2.3 and 2.4), the formal encoding of the arguments corresponds to the position of their referents in a salience hierarchy involving person, animacy, and topicality. Therefore, by extending traditionally pragmatic terms to the entire range of this hierarchy, I will refer to the argument represented by the first constituent after the predicate as Proximate Argument (short: PROX) and to the one represented by the second constituent as Obviative Argument (short: OBV). ${ }^{7}$

That PROX is obligatorily realized is obvious from the fact that the absence of a pronominal clitic from a bivalent predicate indicates the first person singular: ${ }^{8}$

$$
\begin{array}{lllll}
\text { ona } & \text { loy } & \text { pak-na= } \varnothing & \text { kis } & \text { pul-a-cho:-pa } \\
\text { lets_see } & \text { ITN } & \text { count-DR=1SG } & \text { ART.PL.AB } & \text { sweep-DR-BE.inside-AG }
\end{array}
$$

'Let's see, I'll count the cleaning women.'

[EAO_Barredoras 014]

OBV, in contrast, does not need to be overtly realized when it is known from the context. Consider (7), where the manioc (is chinata) mentioned in the first clause is not referred to

\footnotetext{
${ }^{7}$ See Bickel (in press) for first using the labels "proximate" and "obviative" for the nominal constituents in Movima. The capital letters in "Proximate" and "Obviate Argument" used here are intended to show that, while semantically/pragmatically based, they refer to formal categories (cf. Haspelmath 2007: 125). In Haude (2006), the arguments were labeled $\mathrm{ARG}_{1}$ and $\mathrm{ARG}_{2}$, respectively, according to their linear order in the clause.

${ }^{8}$ The first person can optionally be additionally encoded by the element $t$ preceding the predicate (cf. example (54); see Haude 2006: 271f.).
} 
again in the second.

jayna mere', jiran-ni is chinata; jiwa-te-na='ne ney

DSC big nice-PRC ART.PL manioc come-CO-DR=3F here

'The manioc was already big, nice; she brought (it) here.' [EAO_Tomina' 042f.]

PROX is obligatorily expressed after the predicate also when there is a coreferential clauseinitial free pronoun, as illustrated in (8) (see also 3.1 below). This is not the case with OBV, as can be seen in (9).

$$
\text { i’ne jiwa-te-na='ne }
$$

PRO.F come-CO-DR=3F

'She brought (it.)'

$$
\begin{array}{ll}
\text { i’ne } & \text { jiwa-te-na='u} \\
\text { PRO.F } & \text { come-CO-DR=3M }
\end{array}
$$

'He brought her.'

As far as the contrasting phonological attachment of the arguments is concerned, I differentiate between "internal cliticization", represented by an equals sign ( $=$ ), and "external cliticization", represented by a double dash ( -- ). Internal cliticization, which characterized PROX, creates a structure whose stress properties are those of a prosodic word: when a monosyllabic element is internally cliticized, this causes stress shift, stress moving one position to the right. When the host has an open penultimate syllable, this syllable loses its lengthening. ${ }^{9}$ Internally cliticized elements furthermore require a preceding vowel, so that when the host ends in a consonant, the linking vowel $-a$ is inserted; the hiatus created by the cliticization of a vowel-initial element is resolved by a glottal stop. ${ }^{10}$ The phonetic representations in (10) illustrate the stress shift and the shortening of the vowel: with internal cliticization of a syllabic element, as in (10b), stress falls on the last syllable of the host, and not on the penultimate, as is the case when there is no overt pronominal clitic, as in (10a). (Recall from (6) above that the first person singular is zero-encoded on bivalent verbs.)
a. aya:-na=Ø
wait_for-DR=1SG
[a'ja:na]
'I wait for you/him/it etc.'
b. $\quad$ aya $-n a=\underline{u s}$
wait_for-DR=3M.AB
[aja'na?us]
'He waits for him/it etc.'

The occurrence of the linking vowel - $a$ before an internal clitic is illustrated in (11), where an article is cliticized to the host-final consonant $j$. This example also demonstrates that internal cliticization involves articles of DPs as well as pronouns.

$$
\begin{array}{lllll}
\begin{array}{l}
\text { kay- } a-p o j-a \\
\text { eat-DR-CAUS-LV=ART.M }
\end{array} & \text { itila:kwa } & & \text { as } & \text { man } \\
\text { 'The man feeds the dog.' } & & & \text { ART.N.AB } & \text { dog } \\
\text { 'The } & & &
\end{array}
$$

\footnotetext{
${ }^{9}$ This feature distinguishes internal cliticization from canonical suffixation.

${ }^{10}$ The insertion of the linking vowel may give rise to the hypothesis that the glottal stop is an integral part of the pronoun or article analyzed here as vowel-initial, and in fact, this question is not yet completely resolved. The problem with this analysis is the absence of the glottal stop on externally cliticized vowel-initial elements. Therefore, I assume the glottal stop to be an automatic phenomenon on all vowel-initial morphemes (cf. Haude 2006: 38ff.).
} 
External cliticization, which characterizes OBV and the single argument of the intransitive clause, does not have the phonological effects of internal cliticization. Here, stress and length remain in place. Externally cliticized elements can attach to a vowel, as in (12), as well as to a consonant, as in (13), in which case the consonant forms the syllable onset. Furthermore, this process only occurs with pronouns, but not with articles, as can be seen from the occurrence of the glottal stop in (14).

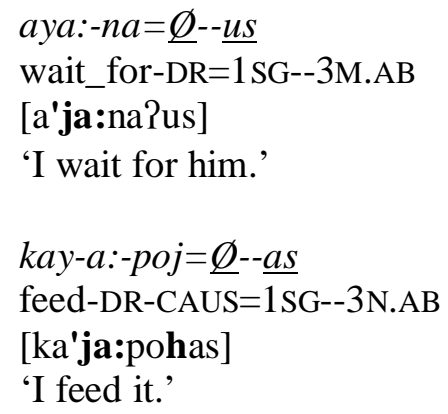

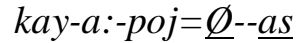

feed-DR-CAUS $=1$ SG- $-3 \mathrm{~N} . \mathrm{AB}$

[ka'ja:pohas]

'I feed it.'

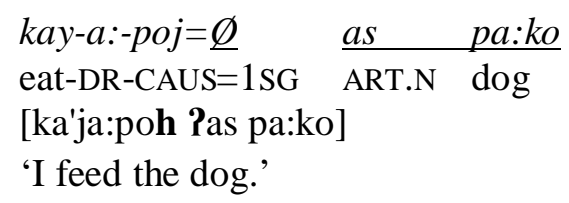

The principal properties that formally distinguish PROX and OBV, apart from linear order, are summed up in Table 3.

Table 3. Formal properties of argument encoding

\begin{tabular}{|c|c|}
\hline PROX (and possessor) ${ }^{11}$ & OBV (and argument of intransitive clause) \\
\hline $\begin{array}{l}\text { internal cliticization }(=) \text { : } \\
\text { stress shift, epenthetic /a/ } \\
\text { pronouns and articles are cliticized } \\
\text { obligatory (also when additionally expressed } \\
\text { in clause-initial position) }\end{array}$ & $\begin{array}{l}\text { external cliticization ( -- ): resyllabification, } \\
\text { no stress shift, no epenthetic /a/ } \\
\text { only pronouns are cliticized } \\
\text { not grammatically obligatory }\end{array}$ \\
\hline
\end{tabular}

In terms of constituency, the two arguments can thus be characterized as internal vs. external to the predicate phrase, as shown in (15). ${ }^{12}$

$$
[[\mathrm{PRED}=\mathrm{PROX}][--\mathrm{OBV}]]
$$

\subsection{The salience hierarchy}

The encoding of the participants as either PROX or OBV is determined by the salience hierarchy in (16), which is subdivided into a deictic (a), a semantic (b), and a pragmatic (c) scale ( > meaning "higher than").

\footnotetext{
${ }^{11}$ For possessor encoding, see 5.1 below.

${ }^{12}$ I owe this analysis to F. Queixalós (p.c.).
} 


$$
\begin{array}{lll}
\text { a. } & \text { person: } & 1>2>3 \\
\text { b. } & \text { animacy: } & \text { human }>\text { non-human animate }>\text { inanimate } \\
\text { c. } & \text { topicality: } & \text { topic }(\text { given })>\text { nontopic }(\text { new })
\end{array}
$$

In a clause describing a two-participant event, the salient participant, i.e. the one that is further to the left on the scale, is encoded as PROX, and the nonsalient participant, i.e. the one that is further to the right, is encoded as OBV. Direct and inverse marking, to be described in 2.4 below, map the participant roles onto these syntactic categories.

Due to the presence of pragmatic factors in the hierarchy, the relative ranking of the three sub-scales is problematic and requires further research. The ranking of the person hierarchy (a) over the animacy hierarchy (b) is clearly formally reflected: there are no pronominal clitics which can encode speech-act participants as OBV. ${ }^{13}$ Therefore, whenever a speech-act participant interacts with a third person, the speech-act participant is encoded as PROX and the third person as OBV. With regard to the animacy hierarchy (b), in contrast, we find cases in which the encoding of the participants goes against the hierarchy (see 4.2 below). This is probably due to the influence of pragmatic factors (scale c). Still, the ranking of the animacy scale over the topicality scale seems to be confirmed by the fact that the apparently contradictory cases are only found when the participant that is nonsalient on the animacy scale is the actor. ${ }^{14}$

\subsection{Direct/inverse marking}

The participant roles of the arguments are indicated by direct or inverse marking on the predicate. Direct marking, carried out by the suffix $-n a$ or its base-internal allomorph $-a$ - in affirmative main clauses, and present in all the above examples of transitive clauses, indicates that PROX is the actor and OBV the undergoer. ${ }^{15}$ The inverse marker -kay indicates that PROX is the undergoer and OBV the actor. A direct and an inverse clause are contrasted in (17) and (18), respectively:

$$
\begin{aligned}
& \text { yok-na='ne as jokme } \\
& \text { catch-DR=3F ART.N bird } \\
& \text { 'She caught the chicken.' }
\end{aligned}
$$

$$
\begin{aligned}
& \text { ew-kay-a='ne os alamre } \\
& \text { hold-INV-LV=3F ART.N.PST wire } \\
& \text { 'A wire held her back.' }
\end{aligned}
$$

[EAO_Escape hija 072]

Example (18) illustrates the use of the inverse when an inanimate entity acts on a human. In (19) below, the inverse form is used to describe an event with an animal acting on a human. The situation described by the inverse clause in (20) is that of an animal being acted upon by the inanimate state of "being full" (denoted by a nominalized form).

\footnotetext{
${ }^{13}$ An exception is the second person plural, which can be encoded as OBV by an external clitic. The ranking of first over second person is reflected by the choice of direct and inverse marking on the predicate (see Haude 2006: 276; Haude to appear a).

${ }^{14}$ On the problem of determining the underlying factors of hierarchies see in particular Comrie (1989: 198f.).

15 The allomorph $-a$ - (represented as $\langle a\rangle$ when infixed to a synchronically unanalyzable base) is inserted in second-syllable position on verbal bases that are morphologically complex, have a monosyllabic and consonantfinal root (CVC), and whose second-syllable position is not occupied by the affix $-k a$ (MLT). The suffix -na occurs in all other environments (see Haude 2006: 323ff.).
} 
jayte os pa:ko, kajte-kay-a= $\underline{u s} \quad \underline{\text { os }}$ pa:ko

then ART.N.PST dog go_to_meet-INV-LV=3M.AB ART.N.PST dog

'Then the dog, the dog went to meet him.'

[JMH_Perro II 043]

$$
\begin{aligned}
& \text { joro-poj-kay-a='ne as jidan-wa='ne i'nes Lus } \\
& \text { sleep-CAUS-INV-LV=3F ART.N be_full-NMZ }=3 F \quad \text { ART.F Luz }
\end{aligned}
$$

'Her being full has made her, Luz (name of a dog), fall asleep.'

[JMH_spont.]

Example (21) illustrates the case with third-person human participants, which are only distinguished by their relative topicality (scale c). In both (21a) and (21c), the topical participant (represented by the pronominal enclitic $=$ 'ne) is encoded as PROX. In the first clause (21a), this participant is the actor, so that the direct construction is used. In the third clause (21c), the actor role is taken over by a newly introduced participant, represented by a DP. Accordingly, the new participant is encoded as OBV, and the inverse construction is used. ${ }^{16}$ (In the intermediate intransitive clause $(21 \mathrm{~b})$, the topical participant is only expressed on the nominalized predicate of the temporal adjunct.)

$$
\begin{aligned}
& \text { a. asko ona-waj-na='ne chot i'ne [...] } \\
& \text { PRO.N.AB know-BE.place-DR=3F HAB PRO.F } \\
& \text { b. chot joy-chet n-os tochi<chi > } k-a=\text { 'ne } \\
& \mathrm{HAB} \text { go-R/R OBL-ART.N.PST small<NMZ >-LV=3F } \\
& \text { c. joy-te-kay-a='ne i’nes a:kay-a='ne } \\
& \text { go-CO-INV-LV=3F ART.F older_sibling-LV=3F }
\end{aligned}
$$

'She knew that (place), she did [...]. (She) had always gone (there) when she was small. Her older sister had always taken her (there).' [EAO_Escape hija 047-049]

\section{The privileged syntactic status of $\mathrm{OBV}$}

As was shown in the preceding sections, Movima displays an asymmetry in argument encoding that is based on the salience hierarchy: OBV, which typically represents the nonsalient participant, has the same formal properties as the argument of the intransitive clause, while PROX, which represents the salient participant, is encoded differently. This is schematized in Figure 1 ( $\mathrm{S}=$ single argument of intransitive clause).

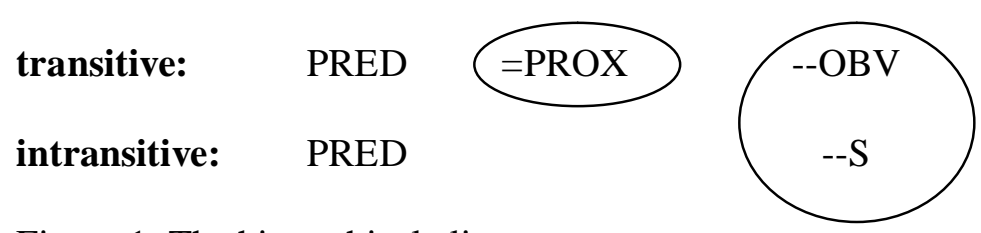

Figure 1. The hierarchical alignment pattern

This section will demonstrate that, moreover, OBV has a privileged syntactic status. Only OBV can be relativized, and it is preferred for topicalization (3.1). For the participant normally encoded as PROX to be relativized or topicalized, a valence-decreasing voice operation is used (3.2). Other constructions which might help to identify the syntactic status of the core arguments (cf. e.g. Keenan 1976; Dixon 1994; Van Valin \& LaPolla 1997) do not show a preference for either of the arguments: the argument of an intransitive clause

\footnotetext{
${ }^{16}$ Note that in general, the expression of the event participants is in line with the findings by DuBois (1987): the salient participant is typically expressed as a pronoun, the nonsalient one as a DP.
} 
coordinated with a transitive clause can either be dropped or overtly expressed, regardless of whether it is coreferential with PROX or OBV of the preceding transitive clause (see Haude in press); reflexive predicates are intransitive, which means that reflexive constructions do not help to determine a privileged argument; purposive clauses, like subordinate clause in general, are formed through nominalization, which involves obligatory possessive argument encoding (see Haude to appear b). No construction has been found yet in which PROX has syntactic control properties. ${ }^{17}$

\subsection{Relative clauses and the marked-topic construction}

Relative clauses follow the DP they modify and are introduced by the particle $d i$ '. They can only have an intransitive argument or OBV as their head, which is not overtly realized. Accordingly, an intransitive relative clause, illustrated in (22), does not contain an overt core argument:

$$
\begin{aligned}
& \text { koro' kos si:doj [di' a:mon no-kot baytim }=\varnothing] \\
& \text { DM.N.AB ART.N.AB monkey REL enter OBL-ART.N.AB.1 field=1SG } \\
& \text { 'There is a monkey that has entered my field.' }
\end{aligned}
$$

When the relative clause is transitive, then either the direct or the inverse construction is chosen, depending on the role of the participant encoded as OBV. In (23), OBV is the undergoer, as indicated by the direct marker on the predicate.

$$
\begin{aligned}
& \begin{array}{llll}
i \text { sos wa:ka } & {[d i} & \text { chik }<a>y e=\underline{i s} & \text { neyru=s bet'i] } \\
\text { ART.PL.PST cow REL find } \angle \mathrm{DR}>=3 \mathrm{PL} . \mathrm{AB} & \text { here=DET grassland } \\
\text { 'the cows which they (the people) had found in this grassland' }
\end{array}
\end{aligned}
$$

In (24), the relativized participant is the actor, as indicated by the inverse morphology.

$$
\begin{array}{llll}
i s & m o: s o=u s & {[d i} & \text { alpani-kay }-a=\underline{u s}] \\
\text { ART.PL } & \text { servant=3M.AB } & \text { REL } & \text { help-INV-LV=3M.AB }
\end{array}
$$

'his servants who helped him'

[EAO_Cbba 053]

Thus, only OBV can be relativized by the above construction. To relativize PROX, which represents the salient participant, a valence-decreasing voice operation is used (see 3.2).

To a lesser degree, the difference in syntactic status of the two arguments also becomes apparent in what can be labeled "marked-topic construction". In this construction, one argument is represented by a free form (usually a free pronoun) before the predicate. It is used to single out a participant that was introduced just before. ${ }^{18}$ The following examples illustrate the marked-topic construction in transitive clauses, (25) with a direct and (26) with an inverse predicate.

$$
\begin{aligned}
& \text { jayna } \quad \underline{a s k o} \quad \text { jam- } a-t e=\text { 'ne } \\
& \text { DSC PRO.N.AB bind-DR-CO=3F } \\
& \text { 'That one [i.e. the mosquito net mentioned just before] she hangs up then.' }
\end{aligned}
$$

[EGA_Alojamiento 035]

\footnotetext{
${ }^{17}$ Only imperative constructions display signs of accusative alignment (as may be expected; cf. Dixon 1994: 131). On both transitive and intransitive imperative verbs, the plural addressee is encoded by the suffix - $k w e t$, which is partly identical with the second-person plural marker for PROX =nkwet.

${ }^{18}$ For more examples see Haude 264f. More research on Movima information structure is needed before the functions of this construction can be characterized more accurately.
} 
asko tat tet-poj-kay- $a=\underline{i s}$ we:ye

PRO.N.AB EV scare-CAUS-INV-LV=ART.PL ox

'That [i.e. the dog that had suddenly appeared], they say, scared the ox.'

[EAO_Ay'ku I 018]

The restriction of topicalization to OBV is not as strong as in the case of relativization. The PROX argument can be encoded by a clause-initial free form as well, as shown in (27). As was already shown by (8) above, the free pronoun then occurs in addition to the obligatory pronominal enclitic. ${ }^{19}$

$$
\begin{aligned}
& \underline{u} \text { 'ko } \quad \text { invitar }-n \boldsymbol{a}=\underline{u}--\underline{k-i s n e} \\
& \text { PRO.M invite-DR }=3 \mathrm{M}--\mathrm{OBV}^{20}-3 \mathrm{~F} \cdot \mathrm{AB} \\
& \text { 'He invited her.' }
\end{aligned}
$$

[EAO_Visita 094]

Note, however, that while this construction is frequent in texts, speakers usually reject it in elicitation and propose the voice construction with kaw instead, to be described in the following section.

\subsection{The voice particle kaw}

It was demonstrated in 3.1 that $\mathrm{OBV}$, which refers to the less salient participant in a twoparticipant event, has the privileged syntactic status. To promote PROX to the privileged status, Movima has a voice operation that allows the former PROX to appear as the single argument of an intransitive clause.

This valence-decreasing operation is carried out by the particle kaw (pronounced as kwey by most speakers) preceding the predicate. ${ }^{21}$ The former PROX is then encoded like the argument of an intransitive clause, and the former OBV, if expressed at all, is marked as oblique. This can be observed in the relative clause in (28b). The corresponding main-clause construction is provided under (28a). senyo:ra
look_after-DR=ART.F lady
a. vel-na='nes
$\begin{array}{ll}\text { kos } & \text { asna }=\emptyset \\ \text { ART.N.AB } & \text { home }=1 \mathrm{SG}\end{array}$
'The lady looks after my house.'
b. i’nes senyo:ra [di' kwey vel-na no-kos asna=Ø] ART.F lady REL kaw look_after-DR OBL-ART.N.AB home=1SG 'the lady that looks after my house'
[EAO_Cbba 243f.]

Example (29b) illustrates the valence-decreasing operation in a marked-topic construction; it contrasts with the transitive construction in (29a), which is from the same text.

\footnotetext{
${ }^{19}$ There is no corresponding inverse construction in the corpus.

${ }^{20}$ The prefix $k$ - (OBV) occurs on third-person OBV enclitics when PROX is or includes a third person.

${ }^{21}$ There is also a tense particle $k w e y$, which indicates the time just preceding the speech moment. One criterion to distinguish the two particles is that the voice particle is pronounced as kaw by some speakers, while this is not the case with the tense particle (see also Haude 2006: 538f.).
} 
a. $\begin{array}{lll}\text { way-na }=\text { 'ne } & \text { os } & \text { jot-kwa } \\ \text { take-DR=3F } & \text { ART.N.PST } & \text { egg-ABS }\end{array}$

'She took the egg.'

[EAO Huevo 007]

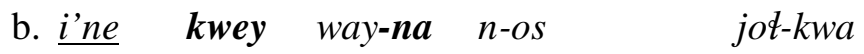

PRO.3F kaw take-DR OBL-ART.N.PST egg-ABS

'It was her who took the egg.'

[EAO Huevo 017]

The valence-decreasing construction is common with direct predicates (where it has an antipassive effect), but it is hardly ever found with inverse ones (where it would have a passivizing effect). In the corpus there is only one example in which the PROX of an inverse clause is topicalized, reproduced in (30b), and none in which PROX is relativized (in fact, the corpus does not seem to contain any example in which a salient undergoer is relativized). The topicalization example in (30b) can, furthermore, be considered exceptional in that it contains the verb jirampojkay 'to be pleased', which seems to be to some degree lexicalized (since the literal translation would be 'to be made nice').

$\begin{array}{llll}\text { a. } & \text { jiram-poj-kay- } a=\underline{i s} \\ \text { nice-CAUS-INV-LV=3PL.AB } & \text { os } & \text { rey } & \text { je'= }=\varnothing \\ \text { ART.N.PST } & \text { MOD } & \text { state=1SG }\end{array}$

'They were pleased by my way of being, you see.'

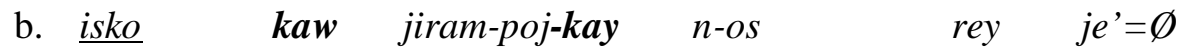

PRO.PL.AB kaw nice-CAUS-INV OBL-ART.N.PST MOD state $=1 \mathrm{SG}$

'They (as opposed to others) were pleased by my way of being, you see.'

[HRR_300703 048]

That the valence-decreasing operation can also operate regularly on the inverse construction only becomes apparent in elicitation. A relative clause is shown in (31b), (31a) illustrating the basic inverse clause. The marked-topic construction is provided in (32).

a.

\begin{tabular}{|c|c|c|}
\hline$u s$ & itila:kwa & $o s$ \\
\hline RT.M & & .N.PST \\
\hline
\end{tabular}

'The snake bit the man.'
b. us itila:kwa [di' kwey lap-kay n-os mimi:di] ART.M man REL kaw bite-INV OBL-ART.N.PST snake 'the man that was bitten by the snake'

$$
\begin{array}{llll}
\text { u'ko } & \text { kwey lap-kay } & \text { n-os } & \text { mimi:di } \\
\text { PRO.3M } & \text { kaw bite-INV } & \text { OBL-ART.N.PST } & \text { snake }
\end{array}
$$

'He was bitten by the snake.'

To sum up, the voice construction with kaw allows the participant encoded as PROX in a transitive clause to become the single argument of an intransitive clause, which can henceforth be topicalized or relativized. This construction is usually found with direct predicates, where PROX is the actor; it is not grammatically restricted to it, however: elicitation shows that the inverse construction, where PROX is the undergoer, can also be subject to the voice operation. 


\section{Analyzing Movima in terms of SAO}

\subsection{The split-alignment pattern}

It was shown above that OBV patterns like the single argument of an intransitive clause and that it has the privileged syntactic status. This means that there is an asymmetry in argument encoding, as was illustrated in Figure 1 above. The pattern is reminiscent of the asymmetry that characterizes constructions as either accusative $(S=A)$ or ergative $(S=O){ }^{22}$ While it was shown above that the asymmetry in Movima is conditioned by different factors than participant roles, it is obvious that the transitive constructions created by direct and inverse marking have different alignment patterns in terms of participant roles and formal encoding ("remapping inverse", cf. Zúñiga 2006). In the direct construction, the privileged argument $(\mathrm{OBV})$ is $\mathrm{O}$, and in the inverse construction, the privileged argument is A. In other words, the direct construction patterns ergatively and the inverse construction accusatively. This split caused by direct and inverse marking is represented in Figure 2. ${ }^{23}$
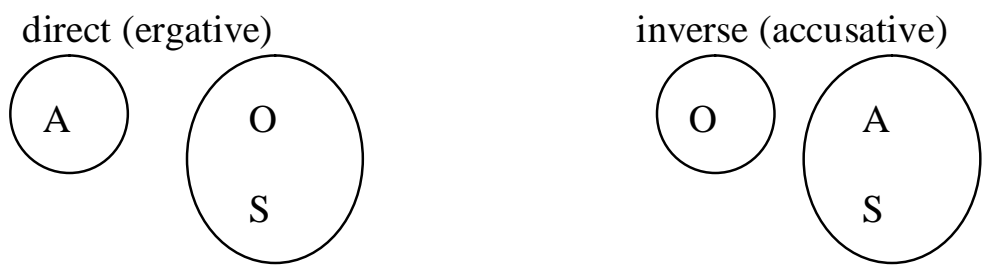

Figure 2. The direct/inverse split pattern

The pattern in Figure 2 is untypical of a hierarchically based alignment split: it is conditioned by the position of the participants relative to each other, not by their absolute position in the indexability hierarchy. The typical cases of hierarchically based alignment splits, in contrast, have a fixed cut-off point, e.g. between speech-act-participants and third persons (cf. DeLancey 1981: 628; Dixon 1994: 83ff.; Silverstein 1976).

While the ergative and accusative pattern are clearly observable, I do not consider it sufficient to describe the Movima system in terms of the SAO model. The underlying rationale that forms the basis of this pattern is the salience hierarchy. The ergative and absolutive patterns simply result from the asymmetry in argument encoding, i.e., the fact that only one of the arguments patterns in the same way as the single argument of the intransitive clause, and this argument can be either $\mathrm{A}$ or $\mathrm{O}^{24}$

Nevertheless, there are signals that Movima has a bias towards ergative argument encoding and alignment. This will be outlined in the following section.

\subsection{The unmarked status of the direct construction}

Typologically, inverse constructions are "marked" as opposed to direct constructions (Croft 2003: 172). In some languages with a direct/inverse system, only the inverse is overtly morphologically marked (cf. Payne 1997: 213f.), while the reversed case, with an unmarked inverse and a marked direct form of the predicate, does not seem to be attested. This is due to the fact that direct constructions describe situations in which salience and agentivity (or "viewpoint" and "starting point"; DeLancey 1981) coincide, which is the prototypical case,

\footnotetext{
${ }^{22}$ In this section, the terms actor and undergoer are replaced by Dixon's (1994) A and O.

${ }^{23}$ In negative and subordinate clauses, where due to nominalization and possessive marking the intransitive argument is encoded in the same way as PROX, this split is reversed (cf. Haude 2006: 306f.).

${ }^{24}$ Direct/inverse systems do not necessarily involve such an asymmetry in argument encoding. In Plains Cree, for example, the argument of an intransitive clause is encoded by the same person affix on the verb as in a transitive clause, no matter whether it is the salient or the nonsalient one (cf. Dahlstrom 1991: 30f., 36, 38).
} 
whereas inverse constructions describe situations in which the two features do not coincide. Also in languages that have overt direct marking, this tendency is reflected by the fact that the direct construction is more frequent (cf. Dahlstrom 1991: 59 for Plains Cree).

The cross-linguistic tendency that the direct construction is pragmatically unmarked as opposed to the inverse can be observed in Movima as well. First of all, the direct construction occurs much more frequently in discourse: a text count of a subset of the corpus revealed that $90 \%$ of the transitive clauses with third-person participants are direct and only about $10 \%$ inverse. (When transitive constructions with at least one speech-act participant are included, the ratio is $80 \%$ for direct and $20 \%$ for inverse clauses.) ${ }^{25}$ In other words, the large majority of transitive affirmative main clauses patterns ergatively.

In addition, there are cases in which we find the direct construction in contradition to the salience hierarchy, in particular, the animacy scale (16b); the inverse construction, in contrast, is not found in opposition to the hierarchy. This is an indication that direct and inverse are not entirely parallel constructions, as was suggested in the previous sections, but that there is an ergative bias: the encoding of the arguments as either PROX or OBV does sometimes not take place on the basis of salience, but on the basis of participant roles, the actor being encoded as PROX and the undergoer as OBV independently of their position in the salience hierarchy.

The pragmatically unmarked status of the direct construction is evident in examples where both third-person arguments are encoded in the same way, i.e., as either bound pronouns or as full DPs. We see this, first of all, in elicitation. In an elicited transitive clause with two DPs, the actor is encoded as PROX and the undergoer as OBV, even when this contradicts the animacy hierarchy, and the verb is marked as direct. This is illustrated in (33a), which is a translation of the Spanish sentence el perro buscó a mi nieto ('the dog looked for my grandson'). The inverse construction in (33b), where the person is encoded as PROX and the animal as OBV, was accepted when I suggested it; however, the speakers explicitly pointed out that it was no better than (33a).

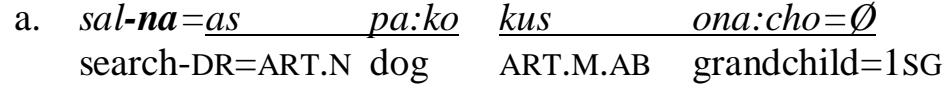
'The dog looked for my grandson.'

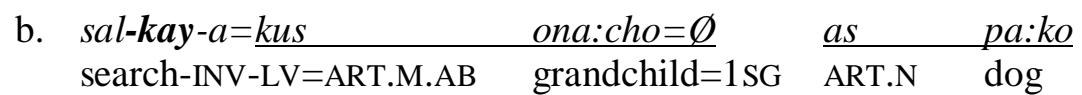

'The dog looked for my grandson.' [e]

The inverse construction is offered spontaneously only when the salient undergoer is established first as the discourse topic, so that it can subsequently be taken up by an anaphoric bound pronoun, as in (34). This is most adequately translated by an English passive.

$\begin{array}{llllll}\text { la' } & \text { joy-chet } & \text { us } & \text { itila:kwa } & \text { n-as } & \text { chapmo } \\ \text { ANT } & \text { go-R/R } & \text { ART.M } & \text { man } & \text { OBL-ART.N bush } \\ \text { che tikoy-kay- } a=\underline{\text { us }} & \text { os } & \text { mimi:di } \\ \text { and kill-INV-LV=3M.AB } & \text { ART.N.PST } & \text { snake } \\ \text { 'The man went into the forest and was killed by a snake.' }\end{array}$

'The man went into the forest and was killed by a snake.'

[e]

\footnotetext{
25 This count is based on a sample of over 40 texts collected in 2002 , with a total duration of 2,45 hours and consisting of approximately 2370 sentences, 960 of them transitive clauses of which 360 describe events with two third-person participants. Most texts stem from one single speaker (2:10hs), but they are of different types, including narratives with humans and/or animals as protagonists, instructions, descriptions, and two conversations.
} 
Example (35) shows that the atypical direct construction can undergo the valence-decreasing process when an actor lower on the animacy scale is topicalized. What would be expected instead, in line with the animacy hierarchy, is the inverse construction without kaw (cf. (26) above).

$$
\begin{array}{lllllll}
\text { as } & \text { yana:we, } & \text { a'ko } & \text { kwey } & \text { tikoy-na } & n \text {-us } & \text { itila:kwa } \\
\text { ART.N } & \text { anaconda } & \text { PRO.N } & \text { kaw } & \text { kill-DR } & \text { OBL-ART.M } & \text { man }
\end{array}
$$

'The anaconda, that was what killed the man.'

The elicited example in (36) illustrates a relative clause in which the relativized argument refers to the salient participant. Here as well, the inverse construction with kaw would be expected ((36b), repeated from (31b) above). However, as with all elicited examples with a nonsalient actor, it was the direct construction (36a) that was offered first.

$$
\begin{aligned}
& \text { a. } \begin{array}{llll}
\text { us } & \text { itila: } k w a & {[\text { di' lap- } \boldsymbol{n a}=\underline{\text { os }}} & \text { mimi:di] } \\
\text { ART.M man } & \text { RELbite-DR=ART.N.PST } & \text { snake }
\end{array} \\
& \text { 'the man that the snake bit' }
\end{aligned}
$$

b. us itila:kwa [di' kwey lap-kay n-os mimi:di]

ART.M man REL kaw bite-INV OBL-ART.N.PST snake

'the man that was bitten by the snake'

The above examples are translations from Spanish and may therefore be considered as being of limited empirical value. Nevertheless, these examples demonstrate that in the absence of contextual information, argument encoding is not necessarily determined by the salience hierarchy; when it is not, the actor is encoded as PROX and the verb is marked as direct.

What is more important is that also in texts, an actor, even when it is lower on the animacy scale (16b), is typically encoded as PROX when it is higher or equal on the topicality hierarchy (16c). The examples again involve the interaction between an animal as actor and a human as undergoer. Consider the subordinate transitive clause (37b), which follows an intransitive subordinate clause in which the animal was established as the topic, (37a). In (37b), the topical participant is taken up by a bound pronoun, which is encoded as PROX, although its referent ranks lower on the animacy scale.
a. $a s k o$
$n-O S$
des-wa $=o s$ mimi:di
PRO.N.AB OBL-ART.N.PST jump-NMZ=ART.N.PST snake
b. che asko n-os la lap-wa=as--k-us
and PRO.N.AB OBL-ART.N.PST DR-bite-NMZ=3N.AB--OBV-3M.AB
'That (was) when the snake jumped, and that (was) when it bit him.' 26
[EAO_víbora 093f.]

Example (38) involves direct speech. The text from which this example was taken does not provide straightforward clues as to the relative topic-hood of the participants: both were introduced before; that they are referred to by full DPs is probably due to the type of utterance, which reflects a spontaneous reaction to an event. Again, the actor, although it is an animal acting on a human, is encoded as PROX, and the construction is direct.

\footnotetext{
${ }^{26}$ In subordinate clauses, the direct marker - $n a$ is optionally replaced by initial CV-reduplication. Due to nominalization, the single argument of the intransitive subordinate clause is encoded as a possessor, i.e. by an internal enclitic (see Haude to appear b); this does not affect the interpretation of the example, however.
} 


$$
\begin{array}{llllll}
\text { jay, } \quad \text { jayna lap-na }=\text { as } & \text { mimi:di } & \text { us } & \text { majni= }= & \text { jankwa }=\varnothing \\
\text { EXCL DSC bite-DR=ART.N } & \text { snake } & \text { ART.M } & \text { offspring=1SG } & \text { say=1SG } \\
\text { 'Ah, now the/a snake has bitten my son!, I said.' } & & & \text { [EAO_víbora 096] }
\end{array}
$$

Example (39), finally, demonstrates that the pragmatically determined choice of the direct over the inverse construction is restricted to third-person participants. Here, the actor is an animal (os awaro), and the two undergoers are the first person singular and a third person (isnos senyo:ra). The verb involving the first person undergoer is marked as inverse with the first person as PROX, in accordance with the deictic scale (16a); the verb involving a thirdperson human undergoer, in contrast, is marked as direct, with the animal encoded by a PROX pronoun.

$$
\begin{aligned}
& \text { os awaro } d a ' \quad \begin{array}{l}
\text { pasinet-kay }=\emptyset \\
\text { ART.N.PST parrot }
\end{array} \text { DUR.NSTD listen-INV=1 SG } \\
& \text { pasinet-na }=\text { as } \quad \text { isnos senyo: } r a \\
& \text { listen-DR=3N.AB ART.F.PST lady } \\
& \text { 'The parrot was listening to me, it was listening to the lady.' }
\end{aligned}
$$

[JMH_Loro 029]

The above examples have shown that under certain circumstances, a participant that ranks lower in the animacy hierarchy (16b) is encoded as PROX in the direct construction. However, we do not find the reversed case, i.e. the inverse construction with the less animate participant encoded as PROX, as illustrated by the hypothetical example in (40).

$$
\begin{aligned}
& \text { ? tikoy-kay-a = as mimi:di } \underline{\text { us itila:kwa }} \\
& \text { kill-INV-LV=ART.N snake ART.M man } \\
& \text { ('The man killed the snake.') }
\end{aligned}
$$

In effect, this means that the direct construction is the default transitive construction, used when in the third-person domain, actor and undergoer are ranked equally on the topicality hierarchy. The inverse construction, in contrast, is restricted to the situation in which the undergoer outranks the actor. The default pattern of transitive affirmative main clauses in Movima, therefore, is ergative.

\section{Towards an explanation}

The preceding sections have shown that in Movima, the syntactically privileged argument is the one that ranks lower than the nonprivileged argument - if not in terms of salience, then in terms of the participant role hierarchy, in which the actor outranks the undergoer (cf. Van Valin and LaPolla 1997: 146; Zúniga 2006: 24), as was demonstrated in 4.2. This is quite remarkable from a cross-linguistic perspective: syntactically ergative languages are rare, and a language whose syntactic organization is determined by salience factors seems to have been unattested up to now. The question is, therefore, how this system may have come into being.

The explanation proposed here is inspired by similar accounts of other unusual nonaccusative alignment systems (see Himmelmann 1991 and Himmelmann 2008 on Philippine languages; Sasse 1991 on Mayan). It is based on the observation that PROX has the same formal properties as a nominal possessor (5.1) and that nouns and verbs, although morphologically distinct, have an almost identical syntactic status (5.2). The synchronic clause structure of Movima, therefore, may have arisen from a reanalysis of predicate nominal constructions. 
Before comparing the syntactic properties of nouns and verbs, it has to be pointed out that morphologically, the two word classes are clearly distinct. Nouns can be incorporated, but verbs cannot: sal-a-mo:ri (search-DR-flower) 'to look for flowers' is fine, but e.g. *sal-ailo:ni [search-DR-walk], with the intended meaning 'to look for a person who walks', is not (for argument incorporation see Haude 2006: 367ff.). Furthermore, while nouns and verbs share some derivational affixes, there are a number of affixes that attach to nouns, but not to verbs, and vice versa. ${ }^{27}$ For instance, nouns, but not verbs, can be combined with the verbalizing suffix -tik to denote an event typically associated with the denotee of the noun (e.g. roya:-tik [house-VBZ] 'to build a house'; see Haude 2006: 486ff.).

\subsection{Possessed nouns}

There are significant parallels between possessed nouns and bivalent verbs in Movima: the possessor is encoded in the same way as PROX, and the addition of the particle kaw has the same effect on possessed nouns as on bivalent verbs.

The encoding of the possessor through internal cliticization is illustrated in (41b) with a DP and in (42) with a pronominal enclitic. The phonetic representations in (41) illustrate the shortening of the penultimate vowel and the stress shift associated with internal cliticization, and (42) illustrates the addition of the epenthetic vowel $-a$ to the possessed noun.

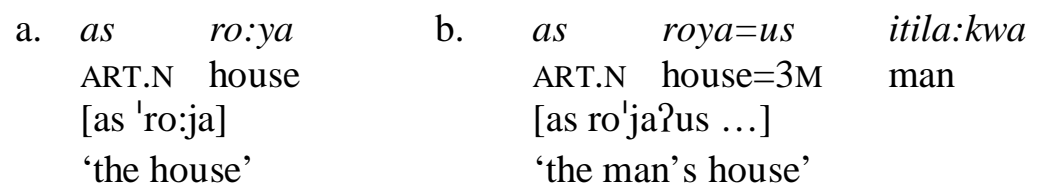

as baytim- $a=$ us

ART.N field- $\mathrm{LV}=3 \mathrm{M} . \mathrm{AB}$

'his field'

Many nouns in Movima, including kinship terms and nouns denoting parts of wholes, are obligatorily possessed. On these nouns, the absence of an internally cliticized element implies the first person singular possessor. The word baytim 'field' is such a noun: ${ }^{28}$

$$
\begin{aligned}
& \text { as baytim= } \varnothing \\
& \text { ART.N field=1SG } \\
& \text { 'my field' }
\end{aligned}
$$

Hence, Movima bivalent verbs are remarkably similar to obligatorily possessed nouns in that zero marking implies the first person singular - something that is common cross-linguistically for inalienable possession marking, but not for verbal argument encoding (Denis Creissels p.c.).

Like bivalent verbs, all nouns that can be possessed can productively be combined with the particle $k a w .{ }^{29}$ The effect is that the referent of the DP is not the denotee of the noun, but its possessor, while the noun is not marked as possessed. The possessed entity is optionally

\footnotetext{
${ }^{27}$ Note that the direct and inverse markers are not restricted to verbal bases alone, but can be attached to nouns, as in lawajes-kay- $a=$ 'ne (remedy-INV-LV=3F) 'He/she/it/they healed her.'

${ }^{28}$ Nouns that are not obligatorily possessed are marked for the first person possessor by the element $t$ attached to the determiner: at ro:ya (ART.N.1 house) 'my house'. This element is optional with obligatorily possessed nouns (as well as with bivalent verbs; see Haude 2006).

${ }^{29}$ Not all nouns can be marked as possessed, including, for example, instrumental nouns with the ending -ni, which also derives monovalent verbs (cf. Haude 2006: 478f.).
} 
encoded by an oblique pronoun, like the former OBV in a verbal clause with kaw (3.2).

$$
\begin{aligned}
& \text { a. is wa:ka } \\
& \text { ART.PL cow } \\
& \text { '(the) cattle' }
\end{aligned}
$$
b. us kwey wa:ka (n-i'ko)
ART.M kaw cow (OBL-PRO.PL.AB)

'the owner of (that) cattle'

Especially with terms denoting kinship or social relations, the function of the marker kaw on nouns is not entirely clear, since both counterparts of these possessive relations can be referred to by lexical items. There are terms that can refer to either part of the relationship, such as ulchat 'in-law' or alwaj 'spouse'; for others, there are completely unrelated lexical items, e.g. nonok 'grandparent' vs. ona:cho 'grandchild'. For three relations, one of the parts is named by a term containing the inverse marker: ya:ya' 'uncle', ya:ni:kay 'nephew'; ${ }^{30}$ ti:ye 'godchild', tiyeni:kay 'godparent'; and the pair a:na 'younger sibling' (presumably containing the direct marker -na) and a:kay 'older sibling'. Therefore, in the text example (45) below, it is not clear why the term kwey a:na is used instead of $a$ :kay-a=us 'his older siblings', illustrated in (46), which is used elsewhere in the text. The speaker confirmed that both expressions are equivalent. ${ }^{31}$

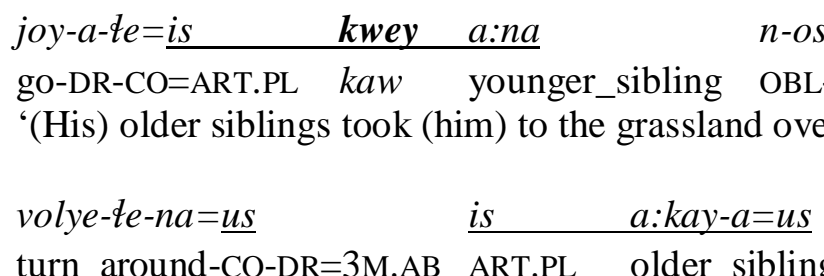

$$
\begin{aligned}
& \text { turn_around-CO-DR=3M.AB ART.PL older_sibling-LV=3M.AB }
\end{aligned}
$$

'He turned around towards his older siblings.'

[EAO_víbora 076]

The identical encoding of possessor and PROX as well as the effect of the particle kaw, together with the fact that PROX does not seem to have syntactic control properties (Section 3 ), indicate strong parallels between possessed nouns and bivalent verbs. This hints at a common historical source of these categories: as will be argued in the following section, it is possible that bivalent verbal predicates have their origin in the reanalysis of possessed predicate nominals.

However, there are also two significant differences. First, while verbs can only take a PROX argument when they are overtly marked as direct or inverse, nouns are marked as possessed without containing morphology of this type (apart from the few cases mentioned above that contain the ending -ni:kay; since this ending is not productive on possessed nouns, they can be considered lexicalized). Second, there is no straightforward evidence at this point that possessors are chosen according to the salience hierarchy, as is the case with PROX. ${ }^{32}$ It is clear, however, that in general, prototypical possessors are high in salience, both with regard to deixis/animacy and to topicality (cf. Siewierska 1998: 29f.), and they share this property with PROX. It is therefore very well possible that the analogy with prototypical possessors is the historical source of the salience-based argument encoding in Movima.

\footnotetext{
${ }^{30}$ The suffix - $n i$ normally derives monovalent verbs denoting a process (see Haude 2006: 493f.); it is also part of many words that are rather to be considered nouns, e.g. wulwanra:ni 'crops' (ibid: 478f.).

${ }^{31}$ Possessive phrases with kaw in transitive clauses are rare in texts, and in elicitation, only isolated DPs were used; therefore, it is impossible to say at this point if their encoding as PROX or OBV plays a role here.

${ }^{32}$ Note e.g. the historically complex expression nononikay- $a=a$ (pet_owner-LV=3N) 'its owner (of the pet)', which is derived from no:no 'my pet' by the inverse marker, and enables the semantically nonsalient entity (the pet) to be encoded as the possessor.
} 


\subsection{The syntactic distribution of nouns and verbs}

Nouns and verbs differ only slightly with respect to their syntactic properties: nouns can function as predicates and verbs can occur inside a DP without any morphological modification. The only syntactic difference is that the argument of a clause with a possessed predicate nominal does not have the same distributional possibilities as OBV of a transitive verbal clause. In this section, I will first discuss predicate nominals and then verbs in DPs.

Movima affirmative clauses have no copula. ${ }^{33}$ To express equation or proper inclusion, nouns can function as predicates without any morphological modification. The argument of an equational clause, illustrated in the examples below, is encoded like the single argument of an intransitive verbal clause (cf. (1)-(4) above): as a phonologically independent DP (47); as an externally cliticized pronoun (48); as a free pronoun in topic position (49); and it can be omitted when it is known from the context, as in (50). Clauses with predicate nominals, therefore, are formally identical to clauses with monovalent verbal predicates.

$$
\begin{aligned}
& \text { mayoro:mo kus alwaj }=\varnothing \\
& \text { housekeeper ART.M.AB spouse }=1 \mathrm{SG} \\
& \text { 'My husband (was) a housekeeper.' }
\end{aligned}
$$

[EAO_Sueño 003]

$$
\begin{array}{lll}
\text { dittej--i'ne, } & \text { choy tolkosya--'ne di:ra } \\
\text { strong--3F } & \text { sure girl--3F }
\end{array}
$$

'She's strong, she's still a young woman of course.'

[Dial. EAO\&AHA]

$$
\begin{array}{llll}
\begin{array}{l}
\text { ayru }=s \\
\text { DM.N.SPK=DET }
\end{array} & \begin{array}{l}
\text { kori:di, } \\
\text { stick }
\end{array} & \begin{array}{l}
\text { 'ko } \\
\text { PRO.N }
\end{array} & \text { lopa:vos, ayru } \\
\text { manioc_stem } & \text { DM.N.SPK }
\end{array}
$$

'This stick here, this (is) a manioc stem, this one here.'

[EAO_Yuca 002]

jayna mo'incho:but

DSC manioc_mass

'(It was) already fermented manioc mass.'

[EAO_Tomina' 066]

When the predicate nominal is a possessed noun, the clause resembles a transitive verbal clause, due to the identical encoding of PROX and the possessor. The argument of a clause with a possessed predicate nominal, however, can only be realized as a free pronoun in topic position, as in (51). The ungrammaticality of encoding the possessed item by an externally cliticized pronoun is illustrated in (52).

$$
\begin{aligned}
& k a<y a: \sim>y-a k, \quad a^{\prime} k o \quad \text { nono }=n \\
& \text { eat<RED >-IRR PRO.N pet=2 } \\
& \text { 'May (it) eat, it's your pet!' }
\end{aligned}
$$

[EAO_spont.]
a. $\underline{a s k o} \quad p a: k o=u s$
PRO.N.AB dog=3M.AB
'It is his dog.'
b. * pa:ko=us--k-as $\operatorname{dog}=3 \mathrm{M} \cdot \mathrm{AB}-\mathrm{-OBV}-3 \mathrm{~N} \cdot \mathrm{AB}$ ('It is his dog.')

Example (53) below illustrates the use of the voice marker kaw with a possessed noun in predicate function. The predicate is the obligatorily possessed noun majni( $w)$ 'offspring'. In the basic construction (53a), the clause-initial free pronoun refers to the possessed entity

\footnotetext{
${ }^{33}$ There may be a copula present in negative main clauses, whose main predicate is nominalized.
} 
denoted by the predicate nominal. In contrast, the free pronoun in $(53 \mathrm{~b})$ refers to the possessor of the predicate nominal, which is not marked as possessed anymore. The particle kaw, therefore, has the same effect in clauses with possessed predicate nominals as in clauses with bivalent predicates (cf. e.g.(28) and (29) above).

$$
\begin{aligned}
& \text { a. } \quad \begin{array}{l}
i{ }^{\prime} \mathrm{m} \\
\text { PRO.PL offspring- } \mathrm{LV}=3 \mathrm{~F}
\end{array} \\
& \text { 'They are her children.' }
\end{aligned}
$$

[EAO_Neighbours 002]
b. isko
kwey
majni
$n i-k i s$
ney $\quad$ di di-n- $a=i s$
PRO.PL.AB kaw
offspring OBL-ART
'They are the parents of their seeds.'
[EAO_Lo''im 002]

The fact that, as was illustrated in (52), the argument of a clause with a possessed predicate nominal is not expressed in the same way as a canonical OBV or as the single argument of an intransitive clause, provides evidence that nominal and verbal predicates are not synchronically equivalent. ${ }^{34}$ However, an interpretation of verbal clauses as diachronically analogous with clauses headed by predicate nominals facilitates the understanding of the syntactic patterns described above.

This interpretation, to be illustrated below, is supported by the fact that not only nouns can function as predicates, but that also verbs can occur inside DPs without any morphological modification:

$$
\begin{aligned}
& \text { nokowa } \& \quad \text { rim }<a:>t e=\varnothing \text { is } \quad \text { ey-na }=n \\
& \text { right_now } 1 \mathrm{SG} \text { buy }\langle\mathrm{DR}>=1 \mathrm{SG} \text { ART.PL want-DR=2 } \\
& \text { 'Now I'll buy the (things) you want.' }
\end{aligned}
$$

[EAO_Abuelo 039]

The referent of a DP containing a verb is not an event, but a participant in the event (in (54), the objects wanted). This participant is determined by the argument structure of the verb: it is the one which would be encoded as the intransitive argument or OBV of the same verb in predicate function. ${ }^{35}$ The article of such a "verbal DP" indicates the referential properties of this participant (see Table 1 above). Example (55) shows that when an actor-oriented monovalent verb is combined with an article, as in (55b), the referent of the phrase is the actor.
$\begin{array}{lll}\text { a. joy-chet } & \text { is } & \text { kwe:ya } \\ \text { go-R/R } & \text { ART.PL } & \text { woman }\end{array}$ '(The) women went.'
b. pe'tete jemay kwe:ya is joy-chet di' kay kay
all pure woman ART.PL.AB go-R/R REL MD eat
'Only women went there to eat.' [EAO_Llamada hija 019]

When an undergoer-oriented monovalent verb occurs in a DP, the referent is the undergoer:

\footnotetext{
${ }^{34}$ Other differences, still to be investigated, may include the use of TAM particles before the predicate (e.g. loy 'intentional'), which may be restricted to verbal predicates.

${ }^{35}$ There are some exceptions, however. A DP containing the monovalent actor-oriented verb ya:lo: we 'to drink' refers to the undergoer (the liquid that is drunk). Likewise, phrases containing verbs with an incorporated undergoer argument refer to the undergoer, even though they are actor-oriented when occurring as predicates (see Haude 2006: 300). It is possible that inside a DP, these verbs are interpreted as nominal compounds headed by the incorporated element.
} 
a. katpit-- $\underline{a s}$

broken--3N.AB

'It was broken.'

[ERC_Sapo 004]

b. jayna $=$ t vel-na $=\underline{\emptyset} \quad \underline{\text { os }}$ rey katpit

$\mathrm{DSC}=1$ look_at-DR=1SG ART.N.PST MOD broken

'Then I looked at the broken (part), you know.'

[ERC_Sapo 016]

Bivalent verbs, i.e., verbs with direct or inverse marking, behave in the same way, the only difference being that they are marked for PROX/possessor. A DP containing a direct-marked verb, as in (57b), refers to the undergoer of the event, which is the participant encoded as OBV when the verb is the predicate, as shown in (57a).

a. $\quad \begin{array}{llll}\text { rimet-na }=\underline{u s} \\ \text { buy-DR }=3 \mathrm{M} . \mathrm{AB}\end{array} \begin{array}{lll}\text { ART.N.PST } & \text { big } & \text { house }\end{array}$

'He bought a big house.'

b. mere' ro:ya jiran-di:-ni os rimet-na=us

big house nice-BE.house-PRC ART.N.PST buy-DR=3M.AB

'A big, nice house (was what) he had bought.'

[EAO_Escape hija 004]

The verb in (58) is inverse, and accordingly, the referent of the phrase in (58b) is the actor.

a. yey-kay- $a=\underline{n}-\underline{-u s}$

want-INV-LV=2--3M

'He loves you.'

$\begin{array}{llll}\text { b. jayna } & \text { ji<wa: > wa } & \text { us } & \text { rey yey-kay- } a=n \\ \text { DSC } & \text { come<MD > }\end{array}$

'The one who loves you, you know, has come already.' [JAO_Naye 052]

Bivalent verbs inside a DP can also be combined with the valence-decreasing particle kaw. This is illustrated in (59). As expected, the phrase is then not marked as possessed anymore; instead, the possessor is the referent of the phrase. (There is no example of this construction with an inverse verb.)

$$
\begin{aligned}
& \text { asko yana:we os kwey yok-na n-os ney daya' } \\
& \text { PRO.N.AB anaconda ART.N.PST kaw catch-DR OBL-ART.N.PST here DUR.NSTD } \\
& \text { 'It (was) an anaconda (what) had caught [the dog] there.' [EGA_Sicurí 049] }
\end{aligned}
$$

The occurrence of a verb inside a DP is pragmatically marked. DPs containing verbs are by far less frequent in texts than those containing nouns (occurring in only $5 \%$ of the clauses in the statistically evaluated subset of the corpus, see footnote 25). In addition, most clauses with a verb in argument function are headed by a predicate nominal (like kwe:ya 'woman' in (55b), mere' ro:ya 'big house' in (57b), yana:we 'anaconda' in (59)). However, it is clear that formally, there is no restriction on the syntactic position of either nouns or verbs. 


\subsection{The equational hypothesis}

Given that nouns can function as predicates of equational clauses and that verbs can occur in DPs referring to an event participant, it is possible to interpret Movima verbs, independently of their position in the clause, as denoting not events, but event participants (see also Haude to appear c). Clauses with verbal predicates can accordingly be analyzed as expressions of equation, similar to predicate nominals. The English paraphrases of the following examples (repeated from (2), (25), and (26), respectively) serve as an illustration of this view. Note that the transitive clauses (61) and (62) have the same structure as clauses with possessed predicate nominals, the OBV argument being encoded by a free pronoun in topic position and PROX rendered as a possessor (cf. (49), (51), (52) above).

$$
\begin{aligned}
& \text { kuyna:nak--i’ne } \\
& \text { play--3F } \\
& \text { 'She (is) (someone who) plays.' (I.e. 'She plays.') } \\
& \text { jayna asko jam-a-te='ne } \\
& \text { DSC PRO.N.AB bind-DR-CO }=3 \mathrm{~F} \\
& \text { 'That (is) her hung-up (one) then.' (I.e. 'That one she hangs up then.') } \\
& \text { asko tat tet-poj-kay-a=is we:ye } \\
& \text { PRO.N.AB EV scared-CAUS-INV-LV=ART.PL ox } \\
& \text { 'That, they say, (was) the scarer of the ox.' (I.e. 'That, they say, scared the ox.') }
\end{aligned}
$$

Also canonical transitive clauses, where both arguments follow the predicate, can be interpreted in this way, despite the fact that there are no parallel constructions with predicate nominals (cf. (52) above):

$$
\begin{aligned}
& \begin{array}{llll}
\text { man }\langle\boldsymbol{a}\rangle \text { ye }=i s & p a: k o & \text { os } & \text { rulrul } \\
\text { meet }\langle\mathrm{DR}\rangle=\mathrm{ART} \text {.PL } & \operatorname{dog} & \text { ART.N.PST } & \text { jaguar }
\end{array} \\
& \text { 'The dogs' found (one) (was) a jaguar.' (I.e. 'The dogs found a jaguar.') }
\end{aligned}
$$

Especially in the case of bivalent verbs, the nominal interpretation is reminiscent of participant nominalization with either actor- or undergoer orientation (cf. Payne 1997: 225ff.): like participles, the verbs "characterize an individual in terms of a certain type of participant role it plays in a state of affairs, e.g. as actor or undergoer" (Sasse 1993: 654). The diachronic scenario of verbal predicates having developed from nominalized forms has frequently been discussed with respect to other non-accusative alignment systems (cf. Comrie 1981: 374ff.; Gildea 2000: 87; Himmelmann 1991: 2; Sasse 1993: 660f.; Siewierska 1998: 31f.; Trask 1979: 398ff.).

For Movima, however, there is no evidence that verbal main-clause predicates have originated from nominalization; as was mentioned above, nouns and verbs are morphologically distinct: verbs cannot be incorporated, and they are not found with certain morphemes that can attach to nouns. Furthermore, morphologically unmarked verbs behave syntactically like verbs marked as direct or inverse: as was illustrated in the previous section, just any verb type can occur inside a DP. ${ }^{36}$ However, even without morphological evidence for nominalization, it may still be possible to consider the similar distributional properties of verbs and nouns as having arisen from a "nounlike" component in the semantics of verbs,

\footnotetext{
${ }^{36}$ Note, however, that the suffix -na does have a nominalizing function on so-called inherently monovalent verb roots and bases (Haude 2006: 339ff.), from which it derives nouns denoting a location. Unlike direct verbs, these derived nouns can be incorporated, they can receive nominal morphology, and when functioning as a predicate, their argument can only be expressed by a free pronoun in topic position.
} 
which primarily seem to characterize the role of a participant in an event rather than the event itself.

\section{Conclusion}

It was shown in this paper that argument encoding in Movima is determined by a salience hierarchy involving deictic, semantic, and pragmatic features, and that the participant lower in this hierarchy is encoded as the syntactically privileged argument. The participant roles of the arguments are indicated by direct and inverse marking on the predicate. The asymmetry in alignment, which provides one core argument with a privileged status, leads to an unusual split-alignment pattern: the direct construction patterns ergatively, with the privileged argument representing the undergoer, and the inverse construction patterns accusatively, with the privileged argument representing the actor. Moreover, it can be shown that the ergative construction is pragmatically unmarked.

Interpreting all verbal clauses as originating from equational intransitive clauses with predicate nominals allows an understanding of this unusual pattern. The intransitive interpretation is possible, first of all, because verbs and nouns have similar distributional properties: both lexical categories can occur equally well as a predicate and inside a DP. Furthermore, there is as yet no evidence that PROX has a syntactic argument status - for the time being, I consider it an argument simply because verbs and nouns are synchronically clearly distinct lexical categories. Historically, PROX may have originated from a phraseinternal modifier, similar to a possessor.

The fact that under this interpretation, OBV is (historically) the only core argument, explains why only this argument is accessible to relativization and topicalization. That this argument encodes the nonsalient participant may be due to the cognitive parallel between possession and transitive actions: a possessive relationship is asymmetrical, and a prototypical possessor is more salient than the entity possessed by it; the same is true of prototypical transitive actions - which is why inverse constructions are typologically marked.

Thus, while in this apparently isolated language it will probably never be possible to identify the diachronic details of the scenario, the data strongly suggest that an explanation of the syntactic patterns of Movima can be found along similar lines as those that are sometimes proposed for other non-accusative systems. The major distinctive property of Movima in this respect is that the syntactic patterns explained in this way are not only based on discourse pragmatics, as in the Philippine language type, or on participant roles, as in predominantly ergative languages, but also on ontological salience.

\section{References}

Bickel, Balthasar. In press. "Grammatical relations typology." In The Oxford Handbook of Linguistic Typology, Jae-Jung Song (ed). Oxford: Oxford University Press.

Comrie, Bernard. 1978. "Ergativity." In Syntactic Typology, Winfred P. Lehmann (ed.). Sussex: Harvester Press. 329-394.

Comrie, Bernard. 1989. Language Universals and Linguistic Typology: Syntax and Morphology (2nd edition). Chicago: The University of Chicago Press.

Croft, William. 2003. Typology and Universals (2nd edition). Cambridge: Cambridge University Press.

Dahlstrom, Amy. 1991. Plains Cree morphosyntax. New York: Garland.

DeLancey, Scott. 1981. "An interpretation of split ergativity and related patterns." Language 57(3): 626-657.

Dixon, R. M. W. 1994. Ergativity. Cambridge: Cambridge University Press. 
DuBois, John A. 1987. "The discourse basis of ergativity.” Language 63(4): 805-855.

Gildea, Spike. 2000. "On the genesis of the verb phrase in Cariban languages: diversity through reanalysis." In Reconstructing grammar. Comparative linguistics and grammaticalization, Spike Gildea (ed.). Amsterdam/Philadelphia: Benjamins. 65-105.

Haspelmath, Martin 2007. "Pre-established categories don't exist: consequences for language description and typology." Linguistic Typology 11(1): 119-132.

Haude, Katharina. 2006. A grammar of Movima. Doctoral thesis, Radboud University Nijmegen. http://webdoc.ubn.ru.nl/mono/h/haude_k/gramofmo.pdf.

Haude, Katharina. In press. "Hierarchical alignment in Movima." International Journal of American Linguistics.

Haude, Katharina. To appear a. "First and second person in Movima." In Argument Coding Systems of Lowland Bolivian Languages, Antoine Guillaume and Françoise Rose (eds.).

Haude, Katharina. To appear b. "Embedded clauses in Movima." In Subordination in South American languages, Rik van Gijn, Katharina Haude, and Pieter Muysken (eds.).

Haude, Katharina. To appear c. "Reference and Predication in Movima." In New Challenges in Typology 2: Transcending the Borders and Refining the Distinctions, Alexandre Arkhipov and Patience Epps (eds.). Berlin: Mouton de Gruyter.

Himmelmann, Nikolaus P. 1991. The Philippine challenge to Universal Grammar. Universität zu Köln, Institut für Sprachwissenschaft: Arbeitspapier Nr. 15 (Neue Folge).

Himmelmann, Nikolaus P. 2008. "Lexical categories and voice in Tagalog." In Voice and Grammatical Functions in Austronesian Languages, Peter Austin and Simon Musgrave (eds.). Stanford: CSLI. 247-293.

Keenan, Edward L. 1976. "Towards a universal definition of 'subject'." In Subject and topic, Charles N. Li (ed.). New York et al.: Academic Press. 303-333.

Payne, Thomas E. 1997. Describing Morphosyntax. A Guide for Field Linguists. Cambridge: Cambridge University Press.

Sasse, Hans-Jürgen. 1991. "Predication and sentence constitution in universal perspective." In Semantic universals and universal semantics, Dietmar Zaefferer (ed.). Berlin et al.: Foris. 75-95.

Sasse, Hans-Jürgen. 1993. "Syntactic categories and subcategories." In Syntax. An International Handbook of Contemporary Research (Vol. 1), Joachim Jacobs, Arnim von Stechow, Wolfgang Sternefeld and Theo Vennemann (eds.). Berlin/New York: de Gruyter. 646-686.

Siewierska, Anna. 1998. "On nominal and verbal person marking." Linguistic Typology 2: $1-55$.

Silverstein, Michael. 1976. "Hierarchy of features and ergativity." Grammatical Categories in Australian Languages, R.M.W. Dixon (ed.). Canberra: Australian Institute of Aboriginal Studies. 112-171.

Trask, Robert L. 1979. "On the origins of ergativity." Ergativity: Towards a Theory of Grammatical Relations, Frans Plank (ed.). London: Academic Press. 385-404.

Van Valin, Robert D. \& Randy J. LaPolla. 1997. Syntax: Structure, Meaning, and Function. Cambridge: Cambridge University Press.

Zúñiga, Fernando 2006. Deixis and Alignment. Inverse Systems in Indigenous Languages of the Americas. Amsterdam/Philadelphia: Benjamins. 


\section{Symbols and abbreviations}

= internal cliticization; -- external cliticization; $\sim$ reduplication; $<>$ infixation; $1=$ first person; $2=$ second person; $3=$ third person; $\mathrm{AB}=$ absential; $\mathrm{ABS}=$ absolute state; $\mathrm{AG}=$ agent nominalization; $\mathrm{ANT}=$ anterior; $\mathrm{ART}=$ article; $\mathrm{BE}=$ bound nominal element; $\mathrm{BR}=$ bound root; CAUS=causative; $\quad \mathrm{CO}=$ co-participant; $\quad \mathrm{DET}=$ determiner; $\quad \mathrm{DM}=$ demonstrative; $\quad \mathrm{DR}=$ direct; DSC=discontinuous; $\quad$ DUR=durative; $\quad E V=$ evidential; $\quad E X C L=$ exclamation; $\quad F=$ feminine; $\mathrm{HAB}=$ habitual; $\mathrm{INV}=$ inverse; IRR=irrealis; $\mathrm{LV}=$ linking vowel; $\mathrm{M}=$ masculine; $\mathrm{MD}=$ middle; MOD=modal; $\mathrm{MOV}=$ moving; $\mathrm{N}=$ neuter; $\mathrm{NEG}=$ negation; $\mathrm{NMZ}=$ nominalization; $\mathrm{NSTD}=$ nonstanding; $\mathrm{OBL}=$ oblique; $\mathrm{OBV}=$ obviative; $\mathrm{PRED}=$ predicate; $\mathrm{PST}=\mathrm{past} ; \mathrm{PL}=$ plural; $\mathrm{PRC}=$ process; $\mathrm{PRO}=$ free pronoun; $\mathrm{RED}=$ reduplication; $\mathrm{REL}=$ relativizer; $\mathrm{R} / \mathrm{R}=$ reflexive/reciprocal; $\mathrm{SG}=$ singular; $\mathrm{SPK}=$ close to speaker; VBZ=verbalizer. 